\title{
Editor's Note: Journal of Blood and Lymph
}

\section{Pierpaolo Di Micco*}

Department of Medicine, UOC Internal Medicine, Ospedale Fatebenefratelli di Napoli, Napoli, Italy

*Corresponding author: Pierpaolo Di Micco, Department of Medicine, UOC Internal Medicine, Ospedale Fatebenefratelli di Napoli, Napoli, Italy, Tel: 00393398078146; E-mail: pdimicco@libero.it

Received date: June 29, 2018; Accepted date: June 29, 2018; Published date: June 30, 2018

Copyright: @ $2018 \mathrm{Di}$ Micco P. This is an open-access article distributed under the terms of the Creative Commons Attribution License, which permits unrestricted use, distribution, and reproduction in any medium, provided the original author and source are credited.

Citation: Di Micco P (2018) Editor's Note: Journal of Blood and Lymph. J Blood Lymph 8: e126. doi: 10.4172/2165-7831.1000e126

\section{Editor's Note}

Blood and lymph are two specialized body fluids with varied functions. Many functions are developed by blood and the between major we can find the regulation of temperature, transportation of respiratory gases the balance of clotting-anticlotting proteins. Blood in fact protects body from loss of blood by clotting. On the other hand an excess of activity of clotting power may lead to hypercoagulable state, endothelial procoagulant dysfunctions and after to thrombosis. Venous thromboembolism is most common of aterothrombosis and may appear in several ways.

Journal of Blood and Lymph is an international peer reviewed journal with open access. Of course the Journal publishes articles related to blood coagulation disorders and venous thromboembolism (VTE) too. In the current volume 8, issue 2, journal of blood and lymph has successfully several articles concerning hypercoagulable state and venous thromboembolism and the number of articles on this topic is increasing in these last 2 years.

In last years the interest toward VTE of the Literature has been increased. VTE has been frequently defined as a big actress that may affect patients with different symptoms and clinical signs appearing during the clinical evolution of other diseases as cancer, COPD, hearth failure [1]. The clinical evolution to pulmonary embolism deriving from lower limb deep vein thrombosis, is the reason because a relevant part of articles on VTE in the literature and guidelines take into account this aspect. However VTE may appear also in other venous vessels as distal veins [2] or in other atypical clinical conditions as hormonal therapies for in vitro fertilization procedures [3] as thalassemia [4]. This atypical association between VTE and clinical disease may influence the choice of antithrombotic treatment in particular to evaluate the safety of direct oral anticoagulants.

Yet, after a diagnosis of VTE and initial treatment of VTE, the duration of long term treatment of a VTE event is still matter of discussion in particular if risk factor for recurrent VTE are still present. In this issue of journal of blood and lymph, Bilici et al. [5] showed that inherited thrombophilia for the presence of prothrombin a20210g and factor Leiden are the most common risk factor for in patients with unexplained appearance of VTE. Moreover, they represent also the most common debated topic about withdrawal of antithrombotic therapy after long term treatment of a VTE and risk of recurrences.

Hypercoagulable state may also have other molecular forms not associated to inherited defects. Usually the acquired molecular thrombophilia recognizes immunopathological origin as for antiphospholipid syndrome but also pathophysiological dysfunction of the endothelial function. In this issue Sandhu et al. [6], summarized the physiological activity of all types of endothelial cells (EC) and their progenitor (EPC). EPC are currently not measured routinely in clinical practice but understanding the role and EPCs in both health and disease are a focus of recent research. A right knowledge of EC and ECP may be useful to better understand pathophysiological and clinical condition in which these dysfunction lead to hypercoagulable state (e.g., the reactive increase of factor VIII) and to hypofibrinolysis (e.g., the increased release of PAI-1).

\section{References}

1. Di Micco P, Visonà A, Di Micco G, Guida A, Jimenez D, et al. (2014) Baseline Analysis on the Outcome of Patients with Deep Vein Thrombosis (DVT) Before the Global Impact of New Oral Anticoagulants in Italy: Data from RIETE Registry. J Blood Lymph 4: 129.

2. Bortoluzzi C, Camporese G, Hong NV, Bernardi E, Di Micco P, et al. (2018) Lights and Shadows of Distal Deep Vein Thrombosis. J Blood Lymph 8: 201.

3. Strina I, Alviggi C, Rosa PD, Avino L, Amoroso R, et al. (2018) Venous Thromboembolism (VTE) and Assisted Reproductive Technologies (ART): A Complex Relationship. J Blood Lymph 8: 199.

4. Tufano A, Gianno A, Coppola A, Esposito R, Conca P, et al. (2018) Recurrent Pulmonary Embolism and Pulmonary Hypertension in a Patient with $\beta$-Thalassemia Intermedia. . J Blood Lymph 8: 205.

5. Bilici M, Corakci BD, Ozturk Y, Ertop S (2018) Commonness of Factor V Leiden, Prothrombin G20210A and Methylenetetrahydrofolate Reductase C677T Mutations among Patients with Thromboembolism in the Western Black Sea (Zonguldak) Region of Turkey. J Blood Lymph 8: 219.

6. Sandhu K, Njoroge W, Yang Y, Harper AGS, Butler R (2018) Endothelial Progenitor Cell Identification, Classification and Nomenclature: A Review. J Blood Lymph 8: 221. 